\title{
Physicomechanical Properties of Rice Husk Pellets for Domestic Combustion in Myanmar
}

\author{
Swe Zin Tun ${ }^{1,2}$, NweNwe Win ${ }^{1}$, Stefan Beisl ${ }^{3}$ and Anton Friedl ${ }^{3}$ \\ 1. Department of Chemical Engineering, Yangon Technological University, Yangon 11011, Myanmar \\ 2. Department of Chemical Engineering, West Yangon Technological University, Yangon 11402, Myanmar \\ 3. Institute of Chemical, Environmental and Bioscience Engineering, TU Wien, Getreidemarkt 9/166, A-1060, Austria
}

\begin{abstract}
Myanmar produces 26.21 million tons of rice annually that results in 5.24 million tons of remaining rice husk of which only around $30 \%$ is used for electricity and heat production in the country. Myanmar needs more energy consumption to develop the agricultural economy and biomass energy in the future of the country. The proximate and ultimate analysis of rice husk and produced rice husk pellets were determined as well as analyzing the physicochemical and mechanical properties. The rice husk pellets without doing size reduction were manufactured in a ring die pellet mill. Loose and pellet-formed rice husk were compared based on the ISO 17225-6 standard for the characterization of herbaceous biomass. Pelletizing increased the bulk density of rice husk by a factor of 4.5 . The net calorific value of Myanmar rice husk pellets was $3.67 \mathrm{~kW} \cdot \mathrm{h} / \mathrm{kg}$ with a moisture content of $7.48 \%$ and the large amount of ash forming constituents. The result showed that the diameter, length, and durability of the produced pellets complied with ISO 17225-6 standard. However, the net calorific value and bulk density could only be partially fulfilled according to the ISO standard depending on the process parameters.
\end{abstract}

Keywords: Rice husk, pellets, bulk density, calorific value, durability.

\section{Introduction}

The 2015 and 2016 Myanmar Statistical Yearbooks reported an annual paddy rice production of 26.21 million tons, which resulted in 5.24 million tons of rice husk from 17.82 million sown acres [1, 2]. Of those 5.24 million tons, $30 \%$ of this rice husk is used in rice husk gasifier and boiler-based system to produce electricity and heat. Given its low bulk density of about $85-110 \mathrm{~kg} / \mathrm{m}^{3}$ [3], the remaining $70 \%$ of the rice husk poses large challenges for disposal in the rice milling. The total amounts of biomass consumption in the rural area of Myanmar, conducted by fire-stove accounts for 8.85 tons per household per annum. The use of rice husk pellets instead of wood fuels plays an important role in cooking and cottage industries in both urban and rural area [4].

Lignocellulosic biomasses, such as herbaceous

Corresponding author: NweNwe Win, Ph.D., professor, research fields: biomass energy and biorefinery. crops, agricultural, and forest residues are the most promising renewable sources for the efficient and clean supply of heat, power, and fuel [5]. In the recent year, these types of biomass feedstock were used to produce pellets for combustion. Sewage sludge-containing proteins and carbohydrates were used as a natural binder to improve the strength of fiber grid in the pellets [6]. Of the many types of pellet mills, flat die pellet mills are widely used employed for small-to-medium scale and up to large scale pellet production and round/ring die pellets mills for medium-to-large scale pellet production [7]. Biomass pelletization has provoked significant interest in Myanmar in recent years as a technique for utilizing residues as an energy source. Several parameters affect the produced quality of pelletized biomass: feedstock variables (feedstock type, moisture content, particle size, shape, and distribution); feedstock composition (cellulose, hemicellulose, lignin, protein, fat, and wax); process variables (die diameter, 
length-to-diameter ratio, die speed, die temperature, pressure, feed rate, binder usage, and pre-heating) to fulfill and achieve customers' requirements for pellet quality and emissions generated by combustion [6, 8]. Density, abrasion, and durability should be measured as the quality parameters for biomass pellets after production within one week to one month to determine their dimensional stability [9].

The aim of this work is to investigate the physicomechanical properties of Myanmar rice husk pellets. This includes compliance with the ISO 17225-6 standard for herbaceous biomass.

\section{Raw Material}

Rice husk before entering the pellet mill and rice husk pellets on a vibrating screen with a round-hole sieve $(3.18 \mathrm{~mm})$ were collected for further analysis. Myanmar Biomass Power Co., Ltd supplied these solid biofuels from a biomass power plant located in the country's Bago Division administrative region, which produces the third largest amount of paddy in Myanmar.

\section{Rice Husk Pelletization}

The pelletizing process was carried out by a pelletizer with a perforated ultra-wear stainless steel round/ring die using three rollers (Yulong 6th generation XGJ 850, $220 \mathrm{~kW}$ ) and a capacity of (2.5-3.5 ton/h). Rice husk was used as delivered without prior drying and moisture content on wet basis of $10.44 \% \pm 0.0115 \%$. Because the press diameter-to-die channel length ratio depends on the raw material, a compression ratio of 1:5.5 was used for the rice husk. The rollers compressed and forced the rice husk under high pressure through the die holes. Each hole acts as an individual mold with a fixed diameter of $8 \mathrm{~mm}$ and a length of 85 $\mathrm{mm}$. The fractional force between the rice husk and die holes increases and leads to elevated temperature. The pellet temperature after discharge was about $93 \pm 2{ }^{\circ} \mathrm{C}$. The pellets showed a soft appearance at elevated temperatures due to lignin

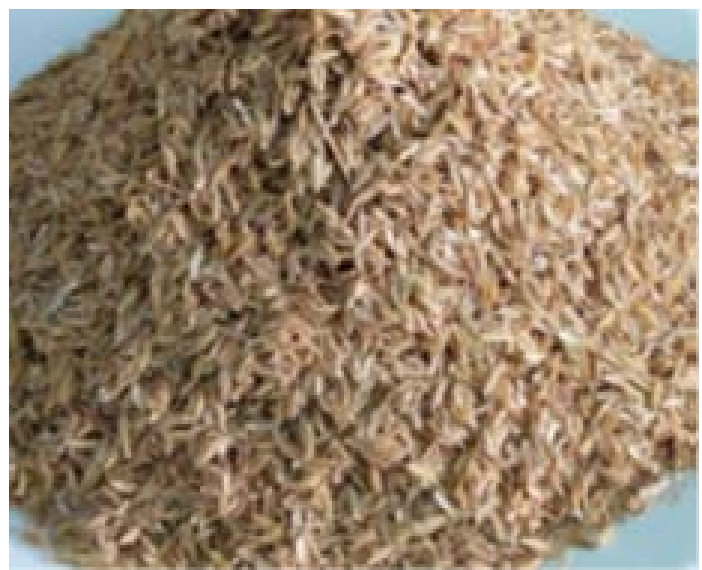

(a)

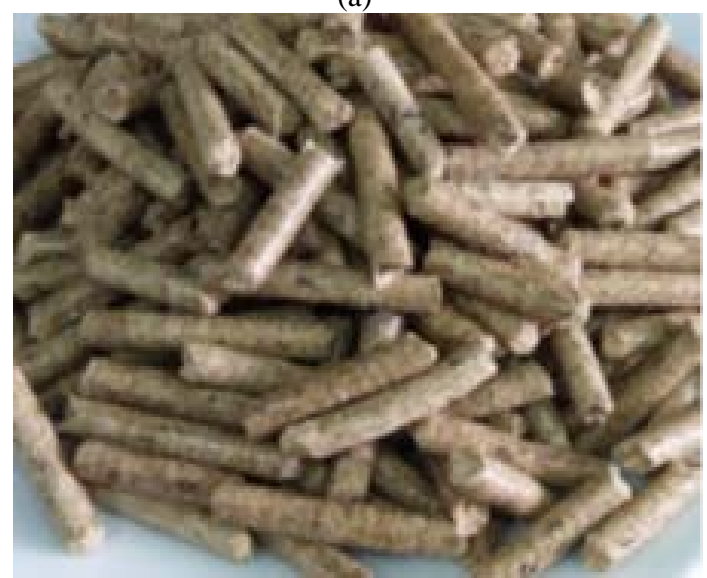

(b)

Fig. 1 Photos of (a) rice husk, and (b) rice husk pellets manufactured.

present in the rice husk, which acts as a binder. The pellets extruded through the die holes were cooled and dried to be solid and strengthened prior to being sieved with a vibrating round-hole screen. The obtained clean and dust-free pellets were packaged in bags for further analysis. Fig. 1 shows the rice husk as a raw material obtained from the rice mills (a) and as manufactured pellets (b).

\section{Analytical Methods}

The cellulose, hemicellulose, lignin, crude protein, crude fiber, and crude fat contents were characterized according to the Verband Deutscher Landwirtschaftlicher Untersuchungs- und Forschungsanstalten (VDLUFA) [10]. Acid detergent fiber (ADF), neutral detergent fiber (NDF) and acid detergent lignin (ADL) were employed to determine 
cellulose, hemicellulose, and lignin contents in the rice husk. Cellulose (ADF-ADL) and hemicellulose (NDF-ADF) were subsequently calculated using these values [11].

\subsection{Proximate Analysis}

The proximate analysis of rice husk and rice husk pellets (solid biomass fuels) was determined by the following standards developed by the American Society for Testing and Materials (ASTM): E871 for moisture content; E872/E897 for volatile matter; E830/D1102 for ash (ASH) and by difference of fixed carbon within the biomass solid fuels [12-14].

\subsection{Ultimate Analysis}

The major solid biofuel constituents such as carbon $(\mathrm{C})$, hydrogen $(\mathrm{H})$, nitrogen $(\mathrm{N})$, and sulfur $(\mathrm{S})$ were determined using a Flash Smart CHNS analyzer (Thermo Fisher Scientific, USA). Oxygen was assumed to represent $100 \%$ of the difference. The data obtained from ultimate analysis were used to calculate the gross calorific value (higher heating value), defined as the amount of heat released by the unit mass or volume of fuel. Eqs. (1) and (2) developed by Channiwala and Parikh $[15,16]$ were applied to calculate the higher heating value (HHV):

$$
\begin{gathered}
H H V=349.1 C+1178.3 H+100.5 S- \\
103.4 O-15.1 \mathrm{~N}-21.1 A S H \mathrm{~kJ} / \mathrm{kg}
\end{gathered}
$$

The relationship between HHV and lower heating value, LHV, is given by:

$$
\mathrm{LHV}=\mathrm{HHV}-\mathrm{h}_{\mathrm{g}}\left(\frac{9 \mathrm{H}}{100}+\frac{\mathrm{M}}{100}\right)
$$

where, $\mathrm{H}$ is the hydrogen percentage and $\mathrm{M}$ is moisture percentage. The latent heat of steam $h_{g}$ is $2260 \mathrm{~kJ} / \mathrm{kg}$.

\subsection{Bulk Density}

The bulk densities were determined in a $5 \mathrm{~L}$ standard container with an inner diameter of $167 \mathrm{~mm}$ and inner height of $228 \mathrm{~mm}$, according to the ISO
17828 (EN15103) [17, 18]. In brief, solid biofuels were slowly poured into the container from a $25 \mathrm{~cm}$ height above the container opening to form a maximum height cone. The container containing solid fuels was compacted by being dropped from a height of $15 \mathrm{~cm}$ to fill the empty space. Filling and compacting were repeated three times until the container overflowed. Next, a strike-off stick $(15 \times 50$ $\mathrm{mm}$ ) was used to remove excess solid biofuels by sliding it across the top of the container. The final weight of the solid biomass fuels was recorded. This procedure was performed five times with $5 \mathrm{~L}$ each of rice husk and rice husk pellets based on their wet bases. The bulk density of solid biomass fuels was calculated using the following Eq. (3):

$$
D_{\text {ad }}\left(\text { at } M_{\text {ad }}\right), \mathrm{g} / \mathrm{cm}^{3}=\frac{\left(M_{2}-M_{1}\right)}{V}
$$

where, $D_{\text {ad }}$ is the bulk wet basis density, $M_{\text {ad }}$ is wet basis moisture content, $M_{1}$ is mass of the empty container, $M_{2}$ is mass of the container fully loaded with pellets, $V$ is volume of the container.

\subsection{Particle Density}

Pellet particle density, including pore volume, was measured using the buoyancy method [19]. The wetting agent (polyethylene glycol) with a $1.5 \mathrm{~g} / \mathrm{L}$ concentration was used to reduce the surface tension. The effect of the temperature on the liquid density was neglected due to laboratory conditions. The pellet particle density $\left(\rho_{u}\right)[20,21]$ was calculated according to Eq. (4):

$$
\rho_{u}=\frac{m_{\mathrm{u}}}{m_{\mathrm{u}}-m_{\mathrm{s}}} \rho_{\mathrm{w}}
$$

where, $\rho_{\mathrm{w}}$ is the density of the liquid at a given temperature, $m_{\mathrm{u}}$ is the weight ofthe test sample in air, and $m_{\mathrm{s}}$ is the weight of the sample in liquid.

\subsection{Energy Density}

Pellet energy density was estimated as a product of the bulk wet basis density $\left(\mathrm{kg} / \mathrm{m}^{3}\right)$ and net calorific value with moisture content (MJ/kg) of the fuels [22]. 


\subsection{Durability}

The mechanical durability of the rice husk pellets was measured according to ISO 17831-1 (ASAE S269.4 standard) [23, 24]. In brief, pellets were pre-sieved with around-hole sieve $(3.65 \mathrm{~mm})$ to remove any fine materials. And $500 \mathrm{~g}$ of initial test pellets were fed in a rectangular stainless steel container with an inner dimension of $300 \mathrm{~mm} \times 300$ $\mathrm{mm} \times 125 \mathrm{~mm}$. A baffle with a dimension of $230 \mathrm{~mm}$ $\times 50 \mathrm{~mm}$ was mounted diagonally on the container's $300 \mathrm{~mm} \times 300 \mathrm{~mm}$ inner side. The filled container was tumbled at $50 \mathrm{rpm}$ for $10 \mathrm{~min}$. The tumbled pellets were sieved again with a $3.65 \mathrm{~mm}$ sieve. The mass of pellets retained on the sieve was recorded and this procedure was performed five times. The pellet durability according to it wet basis was calculated using the following Eq. (5):

$$
\text { Durability }(\%)=\frac{m_{f}}{m_{i}} \times 100
$$

where, $m_{i}$ is the initial mass of pre-sieved pellets before the tumbling process $(\mathrm{g})$ and $m_{f}$ is the remaining pellets' mass after the tumbling process (g) and sieving.

\subsection{Energy Dispersive X-Ray Fluorescence (EDXRF) Analysis}

Rice husk ash composition analysis (expressed as the equivalent oxides for each element) was measured using an EDX-7000, Energy Dispersive X-ray fluorescence spectrometer (Shimadzu, Japan) at $50 \mathrm{kV}$ and $13 \mu \mathrm{A}$. Samples were scanned from $0-40 \mathrm{keV}$ for $60 \mathrm{~s}$ at ambient atmosphere.

\subsection{Statistical Analysis}

Design-Expert software, version 11 (DX11) was used to analyze the results obtained from experiments that were run at least three times using the methods described above. The weight percent from the experimental data in this study were expressed as the mean \pm SD (standard deviation). The level of significance, 0.05 , corresponds to a $95 \%$ confidence interval.

\section{Results and Discussion}

Rice husk's organic composition is mainly comprised of cellulose, hemicellulose, lignin, and silica, as well as small quantities of metal oxides. Table 1 shows rice husk ash composition, which most likely consists of fat, crude protein, and fiber. The rice husk cellulose content was $41.70 \% \pm 0.3606 \%$. Cellulose content has not been a suitable adhesive for biomass pelletizing. However, the lignin content, which acted as an adhesive to the cellulose fiber within the rice husk, was $13.70 \% \pm 0.1900 \%$. This subsequently contributed to the formation of pellets without binders. The silicon dioxide $\left(\mathrm{SiO}_{2}\right)$ content observed in the rice husk ash was $96.06 \% \pm 0.6463 \%$. Despite silica being most prevalent, the rice husk ash also contained a small amount of oxides, with potassium oxide having the highest concentration of the elemental oxides. Alkali metal oxide as potassium oxide can react with silica to form silicates, which may lead to sintering within the reactor. Calcium oxide $(\mathrm{CaO})$ can also react with sulfur to produce sulfate; however, the rice husk sulfur content was low $(0.05 \% \pm 0.0058 \%)$.

Table 2 shows the proximate analysis, ultimate analysis, and higher heating value (HHV), which are the most important data for characterizing lignocellulosic biomass. The moisture content in the rice husk decreased from $10.44 \% \pm 0.0115 \%$ to $7.48 \%$ $\pm 0.1514 \%$ after pelletizing due to fraction-generated heat that occurred during the process. In addition, some surface moisture from the pellets was removed while the pellets were carried on the conveyor before packaging. Solid biofuel ash content was $16.14 \% \pm$ $0.2297 \%$ in mass given its constituents like silicon, potassium, calcium and a trace amount of inorganic constituent oxide in the rice husk, as exhibited in Table 1. Increasing the biomass ash content lowers the heating value risk of fouling and slagging inside the reactor as well as dust emission. The main chemical elements, carbon $(\mathrm{C})$, hydrogen $(\mathrm{H})$, and oxygen $(\mathrm{O})$ could determine the calorific value of a fuel. The 
Table 1 Chemical composition of rice husk and inorganic constituents of rice husk ash.

\begin{tabular}{llll}
\hline $\begin{array}{l}\text { Rice husk } \\
\text { chemical composition }\end{array}$ & $\begin{array}{l}\text { wt \% on wet-basis } \\
\text { Mean } \pm \text { SD }\end{array}$ & $\begin{array}{l}\text { Rice husk ash } \\
\text { constituents }\end{array}$ & $\begin{array}{l}\text { wt \% on dried-basis } \\
\text { Mean } \pm \text { SD }\end{array}$ \\
\hline Cellulose & $41.70 \pm 0.3606$ & Silicon dioxide & $96.06 \pm 0.6463$ \\
Hemicellulose & $22.10 \pm 0.3000$ & Potassium oxide & $2.51 \pm 0.3345$ \\
Lignin & $13.70 \pm 0.1900$ & Calcium oxide & $0.55 \pm 0.1110$ \\
Fat & $0.05 \pm 0.0900$ & Sulfur trioxide & $0.41 \pm 0.0686$ \\
Crude protein & $0.25 \pm 0.0252$ & Iron oxide & $0.20 \pm 0.1131$ \\
Crude fibre & $4.29 \pm 0.0252$ & Manganese (II) oxide & $0.21 \pm 0.0007$ \\
\hline
\end{tabular}

Table 2 Proximate, ultimate analysis, and HHV of rice husk and produced rice husk pellets.

\begin{tabular}{lll}
\hline Fuel properties & $\begin{array}{l}\text { Rice husk } \\
\text { Mean } \pm \text { SD }\end{array}$ & $\begin{array}{l}\text { Produced rice husk pellets } \\
\text { Mean } \pm \text { SD }\end{array}$ \\
\hline Proximate analysis (wt \%) & & $7.48 \pm 0.1514$ \\
\hline Moisture & $10.44 \pm 0.0115$ & $16.07 \pm 0.0923$ \\
Ash & $16.14 \pm 0.2297$ & $62.53 \pm 0.0135$ \\
Volatile matter & $62.95 \pm 0.3904$ & $13.92 \pm 0.1204$ \\
Fixed carbon & $10.47 \pm 0.4509$ & \\
\hline Ultimate analysis (wt \%) & & $40.95 \pm 0.0370$ \\
\hline Carbon, C & $40.30 \pm 0.0640$ & $5.10 \pm 0.0370$ \\
Hydrogen, H & $5.26 \pm 0.0619$ & $0.30 \pm 0.0129$ \\
Nitrogen, N & $0.36 \pm 0.0330$ & $0.05 \pm 0.0037$ \\
Sulfur, S & $0.05 \pm 0.0058$ & $53.60 \pm 0.0673$ \\
Oxygen, O & $54.03 \pm 0.0374$ & $1.48 \pm 0.0098$ \\
\hline Elemental mole ratio & & $0.98 \pm 0.0021$ \\
\hline H/C & $1.56 \pm 0.0206$ & \\
O/C & $1.01 \pm 0.0013$ & $14.42 \pm 0.0607$ \\
Calorific value (MJ/kg) & & \\
Calculated higher heating value (HHV) & $14.34 \pm 0.0573$ & \\
\hline
\end{tabular}

Table 3 Physical, mechanical properties of rice husk and produced rice husk pellets, and ISO 17225-6 specifications for pellet produced on an herbaceous biomass wet basis.

\begin{tabular}{llll}
\hline Fuel properties & $\begin{array}{l}\text { Rice husk } \\
\text { Mean } \pm \mathrm{SD}\end{array}$ & $\begin{array}{l}\text { Produced rice husk pellets } \\
\text { Mean } \pm \mathrm{SD}\end{array}$ & ISO 17225-6 \\
\hline Physical property & & & $6-10$ \\
\hline Width or diameter $(\mathrm{mm})$ & $(0.62-2.48)$ & $7.88 \pm 0.0212$ & $3.15<L \leq 40$ \\
Length $(L)(\mathrm{mm})$ & $6.93-7.53$ & $9.97 \pm 0.3021 \leq \mathrm{L} \leq 75 \pm 0.5630$ & $\geq 4$ \\
Net calorific value $(\mathrm{kW} \cdot \mathrm{h} / \mathrm{kg})$ & $3.62 \pm 0.0451$ & $3.67 \pm 0.0534$ & $\geq 600$ \\
Bulk density $\left(\mathrm{kg} / \mathrm{m}^{3}\right)$ & $130.38 \pm 0.0306$ & $565.03 \pm 0.1760$ & $\mathrm{NA}$ \\
Energy density $\left(\mathrm{GJ} / \mathrm{m}^{3}\right)$ & $1.69 \pm 0.0015$ & $7.53 \pm 0.0694$ & $\mathrm{NA}$ \\
Particle density $\left(\mathrm{kg} / \mathrm{m}^{3}\right)$ & - & $1.32 \pm 0.1901$ & $\geq 97.5$ \\
\hline Mechanical property & & & $>99 \pm 0.0756$ \\
\hline Durability $(\%)$ & - & & \\
\hline
\end{tabular}

NA means "Not Announced".

calorific value of the rice husk pellets was slightly higher than that of the rice husk. This was because of a moderate decrease in the rice husk pellets' elemental mole ratios, $(\mathrm{H} / \mathrm{C})$ and $(\mathrm{O} / \mathrm{C})$, compared to the rice husk's elemental ratio. In contrast, an increase in elemental mole ratios and moisture content reduces fuel's calorific value.

Table 3 shows the physicomechanical properties of rice husk based on wet basis and manufactured rice husk pellets, and also provides a comparison of 
produced pellets and those produced from herbaceous biomass according to ISO 17225-6 standards [25]. Furthermore, Table 3 shows that the particle density of the rice husk pellets produced from rice husk without modifying its particle size and moisture content was $1.32 \mathrm{~kg} / \mathrm{m}^{3}$. The bulk density of the rice husk pellets was 4.5 times higher than that of the rice husk, which leads to improvements in handling and transportation, while also decreasing the storage, transportation and storage footprint area. In addition, the pellet energy density also increased due to its increased bulk density and net calorific value. Missagia and Guerroero [26] reported that the net calorific value of Brazilian rice husk pellet was 3.61 $\mathrm{kW} \cdot \mathrm{h} / \mathrm{kg}$ with a moisture content of $8.5 \%$. The rice husk ranged from 5-6 on the Moh's scale of hardness, which involves scratching the material with apatite and feldspar metal. The physicomechanical properties of the manufactured rice husk pellets were then compared with ISO 17225-6 standards while the produced rice husk's diameter, length, and durability complied with these standards, net calorific value and pellet bulk density were influenced by moisture content, particle size, feedstock composition, and machine-specific parameters, which affected whether it met these standards.

\section{Conclusions}

Rice husk and rice husk pellets made in a ring die pellet machine were compared based on their physicomechanical properties and thermal stabiliy. The silicon and potassium, which acted as an ash-forming oxide in the rice husk feedstock, represented the majority of the composition with $96.06 \%$ and $2.51 \%$, respectively. The net calorific value of Myanmar rice husk pellets was $3.67 \mathrm{~kW} \cdot \mathrm{h} / \mathrm{kg}$ with a moisture content of $7.48 \%$ and the large amount of ash forming constituents. The pelletizing process decreased the rice husk moisture content due to the emerging fraction heat. The amount of lignin as a basic binding agent was $13.70 \%$ (wet basis). The bulk density was increased 4.5 times by pelletizing the rice husk. Increasing the bulk density in pellet promotes better handling and feeding of the biomass feedstock with less dust formation and improves transportation and storage. Next, the diameter, length, and durability of rice husk pellets manufactured met the ISO 17225-6 standard. The net calorific value and bulk density of pellets produced were moderately lower than the standard due to depending on the composition of rice husk, particle size of raw materials and depending on the holding time in press channel.

\section{Acknowledgements}

The authors are grateful for the financial support of the Fundamental Research Funds from the Ministry of Education to the Yangon Technological University and U Nyi Hla Nge Foundation under the grant number $\mathrm{FB} / \mathrm{D}(7) / 2019 / 1$ and for the rice husk, and rice husk pelletsprovision from Myanmar Biomass Power Co., Ltd.

\section{References}

[1] Ministry of Planning and Finance. 2016. Myanmar Statistical Yearbook. The Government of the Republic of the Union of Myanmar.

[2] Nelson, R., and Aung, S. M. 2019. Burma-Union of Grain and Feed Annual. Grain report number: BM 9002.

[3] Missagia, B., Guerrero, C., Narra, S., Sun, Y., Ay, P., et al. 2011. "Physicomechanical Properties of Rice Husk Pellets for Energy Generation.” J Energy and Fuels 25 (12): 5786-90. doi.org/10.1021/ef201271b.

[4] Maw, T., and Dagmar, J. 2019. "Biomass Sources and Energy Potential for Energy Sector in Myanmar: An Outlook.” J Resources 8: 102. doi:10.3390/resources8020102.

[5] Chen, W.-H., Peng, J., and Bi, X. T. 2015. “A State-of-the-Art Review of Biomass Torrefaction, Densification and Applications.” $J$ Renewable and Sustainable Energy Reviews 44: 847-66. doi: org/10.1016/j.rser.2014.12.039.

[6] Mostafa, M. E., Hu, S., Wang, Y., Su, S., Hu, X., et al. 2019. “The Significance of Palletization Operation Conditions: An Analysis of Physical and Mechanical Characteristics as well as Energy Consumption of Biomass Pellets.” J Renewable and Sustainable Energy Review 105: 332-48. doi: org/10.1016/j.rser.2019.01.053. 
[7] Angela, G.-M., and Carpio, M. 2015. "Biomass Pelletization Process." In WIT Transactions on State of the Art in Science and Engineering, Vol. 85. Southampton: WIT Press, pp. 53-66. doi: 10.2495/978-1-84566-062-8/004.

[8] Tumulura, J. S. 2018. "Effect of Pellet Die Diameter on Density and Durability of Pellets Made from High Moisture Woody and Herbaceous Biomass.” J Carbon Resources Conversion 1: 44-54. doi.org/10.1016/j.crcon.2018.06.002.

[9] Adapa, P. K., Tabil, L. G., and Schoenau, G. J. 2011. "Grinding Performance and Physical Properties of Non-treated and Steam Exploded Barley, Canola, Oat and Wheat Straw.” J Biomass and Bioenergy 35: 549-61. doi: 10.1016/j.biombioe.2010.10.004.

[10] Michael, D.-Z., Moeller, L., and Gorsch, K. 2016. Biomass Energy Use: Collection of Methods for Biogas, Vol. 7.

[11] Zhao, X., Gong, J., Zhou, S., Yang, K. O., Song, X., et al. 2015. "Effect of Fungal Treatments Rape Straw on Chemical Composition and in Vitro Rumen Fermentation Characteristics.” J Bioresour Technol 10 (1): 622-37.

[12] ASTM Designation: E 871-82. 1998. Standard Method for Moisture Analysis of Particulate Wood Fuels.

[13] ASTM Designation: E 872-82. 1998. Standard Test Method for Volatile Matter in the Analysis of Particulate Wood Fuels.

[14] ASTM Designation: D 1102-84. 2001. Standard Test Method for Ash in Wood.

[15] Channiwala, S. A., and Parikh, P. P. 2002. "A Unified Correlation for Estimating HHV of Solid, Liquid and Gaseous Fuels.” J. Fuel 81: 1051-63. doi.org/10.1061/s0016-2361(01)00131-4.

[16] Ferreira, S., Monteiro, E., Brito, P., Castro, C., Calado, L., and Vilarinho, C. 2019. "Experimental Analysis of Brewers' Spent Grains SteamficGasi ation in an Allothermal Batch Reactor.” J. Energies 12: 912. doi:10.3390/en1205091.

[17] EN ISO 17828. 2016. Solid Biofuels: Determination of Bulk Density.

[18] EN 15103. 2009. Solid Biofuels: Determination of Bulk Density.

[19] Martynenko, A. 2014. "True, Particle, and Bulk Density of Shrinkable Biomaterials: Evaluation from Drying Experiments.” Drying Technology 32 (11): 1319-25. doi: 10.1080/07373937.2014.894522.

[20] Rabier, F., Temmerman, M., Bohm, T., and Hartmann, H. 2006. "Particle Density Determination of Pellets and Briquettes.” J. Biomass and Bioenergy 30: 954-63. doi:10.1016/j.biombioe.2006.06.006.

[21] EN ISO 18847. 2016. Solid Biofuels, Determination of Particle Density of Pellets and Briquettes.

[22] Obernberger, I., and Thek, G. 2010. The Pellet Handbook: The Production and Thermal Utilization of Pellets. ISBN: 978-1-84407-631-4.

[23] EN ISO 17831-1. 2015. Solid Biofuels: Determination of Mechanical Durability of Pellets and Briquettes.

[24] ASABE Standards S269.4 2006. Cubes, Pellets and Crumbles-Definitions and Methods for Determining Density, Durability and Moisture Content. St. Joseph, MI: American Society of Agricultural Engineers.

[25] ISO17225-6. 2014. "Part 6: Graded Non-woody Pellets." In Solid Biofuels-Fuel Specifications and Classes.

[26] Missagia, B., Guerrero, C., Narra, S., Krautz, H. J, and Ay, P. 2010. "Physical Characterization of Brazilian Agricultural and Forestry Residues Aiming the Production of Energy Pellets.” In 18th European Biomass Conference and Exhibition, Lyon, France. 